\title{
Poética da relação em um missosso angolano
}

\author{
Wellington Marçal de Carvalho*
}

\begin{abstract}
RESUMO
Este estudo objetiva apresentar uma leitura do romance Mãe, materno mar, do angolano Boaventura Cardoso, amparada em reflexões teóricas sobre a noção de literatura menor e a categoria da produção cultural ancorada nas tradições orais do povo angolano, notadamente os missossos. $\mathrm{O}$ intento é, sobretudo, demonstrar que esse romance permite, exemplarmente, pelo menos no espaço da literatura, a materialidade do que se convencionou nomear poética da relação. Foi possível concluir que essa obra recupera, enquanto exercício de sabedoria, as marcas da tradição viva e, para além disso, enceta uma escrita que coloca em relação culturas díspares em uma posição dialógica para a feitura de um mosaico tipicamente angolano: o missosso.
\end{abstract}

Palavras-chave: Literatura angolana. Tradição oral. Literatura menor. Poética da relação.

\section{Introdução}

A Relação só pode tramar-se entre entidades persistentes.

(GLISSANT, 2005, p. 125)

O percurso de leitura do romance Mãe, materno mar (2001), de autoria do angolano Boaventura Cardoso, publicado em 2001, amparar-se-á nas reflexões teóricas acerca da noção de literatura menor e da produção cultural ancorada nas tradições orais do povo angolano, notadamente os missossos, objetivando, sobretudo, demonstrar que esse romance permite, exemplarmente, pelo menos no espaço da literatura, a materialidade do que se convencionou nomear, com Glissant, "poética da relação." (GLISSANT, 2005, p. 105).

Ainda que se corra o risco de mutilar a riqueza da obra, julga-se necessário uma tentativa, diminuta, de apresentar o enredo do texto de Boaventura Cardoso. Em linhas gerais, o romance trata de uma grande viagem de trem partindo de Malange, no interior de Angola, em direção a Luanda, deslocamento que normalmente se faria em cinco horas, mas, insolitamente, teve sua duração dilatada em quinze anos. 
Ao fim, constatar-se-á que essa viagem, ricamente acidentada, alegoriza o engodo e a frustração do povo angolano (SECCO, 2001, p. 5). Em outras palavras, é um testemunho sociológico da época recente daquele país e pode-se dizer do momento atual que se vive (ANDRADE, 2005, p. 63).

Como verifica Luís Kandjimbo (2011), esse comboio pode ser entendido como um símbolo de movimento e, para além disso, não desempenha apenas a função de meio de transporte. Pelo contrário, transforma-se em espaço habitacional e simboliza, por outro lado, o locus da desordem e do caos. Para Carmen Lúcia Tindó Ribeiro Secco:

A narrativa se estrutura em torno do tema e das metáforas da viagem. Viagem de Manecas, o protagonista, que parte para a capital à procura de emprego, mas conserva ainda certos resquícios da infância mimada, não conseguindo libertar-se das amnióticas águas maternais. Viagem pelos mitos, ritos e religiosidades; pela memória, cultura e história de Angola. Viagem também pela própria escrita, em busca, cada vez mais, de uma linguagem, que, captando e recriando expressões, formas e maneiras angolanas de falar e pensar, possa, acrescida da lucidez política e da capacidade de elaboração poética do discurso enunciador, fazer uma profunda e crítica leitura do país. (SECCO, 2001, p. 15).

Conforme se demonstrará, ao se pensar o texto de Boaventura Cardoso como um grande missosso, parametriza-se uma releitura da história da formação da angolanidade sob a égide de uma estética da relação.

\section{Missosso enquanto literatura menor rumo à totalidade-mundo}

... a aparência do real oblitera aquilo que está sob o real: o rastro/resíduo das condições iniciais.

(GLISSANT, 2005, p. 119)

É relevante uma ligeira incursão na teoria sobre um modo peculiar de narração, oriundo das tradições orais, especificamente, os missossos, já que o texto de Mãe, materno mar aparenta nutrir-se dessa manifestação própria à tradição oral angolana.

$\mathrm{O}$ cotejo de parte da fortuna crítica dedicada a esse romance de Boaventura valida a hipótese de tratar Mãe, materno mar como um estupendo missosso, como mencionado, por exemplo, em Gonçalves (2007, p. 411, 418), Padilha (2005, p. 144-145), Saraiva (2008, p. 67) e Secco (2001, p. 2; 2003, p. 238). Para explicar, de forma sucinta, o que vem a ser o missosso, convocar-se-á Padilha, que nos ensina que, 
dentro do quadro de tradição oral autóctone, é aquela forma narrativa percebida pelo natural como sendo totalmente ficcional, no sentido em que vê nela um produto apenas do imaginário, algo não acontecido no real empírico, pois pertencente apenas à ordem da fantasia. (...) Dramatizam-se, na cena discursiva do missosso, de um lado, as aspirações individuais e, de outro, as necessidades primordiais do grupo, preparando-se cada indivíduo para a realidade clânica e fundamentando-o nos segredos e mistérios que traçam o perfil comunitário. Isso explica por que há também um parentesco entre missosso e rito de iniciação, pelo fato de ambos reelaborarem simbolicamente os mitos fundadores que, em última análise, arquitetam aquele mesmo perfil. (...) O pensamento animista está, pois, na base das várias categorias de personagens existentes nos missossos, sendo o elemento sobrenatural - personagem ou acontecimento - o que vai dar a especificidade discursiva daquela forma narrativa. (...) Contém em seu bojo o jogo metalinguístico de desvelamento do processo de contar, o que se revela no procedimento narrativo do encaixe. (...) O prazer está, algumas vezes, menos no que se conta do que no como se conta, ou seja, nesse desdobrar-se da narrativa sobre si mesma, narcisicamente se vendo ao espelho da cena discursiva e negando-se a deixar-se morrer. (PADILHA, 1995, p. 19-28 - destaques da autora).

A enormidade de extratos narrativos, corporificados pelas várias estórias, apensas à linha mestra que conduz o enredo principal (a viagem de trem de Malange a Luanda), caracteriza um artifício próprio do missosso, cuja performance narrativa, originalmente de matriz oral, dispõe em posição dialógica espaços da alteridade densamente carregados de traços da identidade local. De acordo com Secco:

\begin{abstract}
Mãe, materno mar, em sua polifônica urdidura romanesca, se organiza como um grande missosso... Escritura em trânsito, alegoria das transformações verificadas no imaginário sociocultural angolano da pós-Independência, em particular dos anos $80 \mathrm{em}$ diante, o romance opera com o tema e as metáforas da viagem. (SECCO, 2001, p. 15).
\end{abstract}

O missosso também permite a composição plural dos sujeitos enunciadores de discurso. De caráter polifônico, várias vozes são convocadas ao longo do romance para narrar, cada uma a seu modo, acontecimentos sobrenaturais, pacificamente misturados com fatos do cotidiano daquela insólita viagem - talvez assim o fazendo como estratégia de sobrevivência perante a infindável enxurrada de intempéries e avarias da locomotiva. Esse caudal discursivo, cujo contato pode levar à vertigem o leitor, em que caminham lado a lado o real e o incomum, já 
quase sendo impossível a definição das fronteiras que os separam, cristaliza o exercício de estilo de Boaventura Cardoso mergulhado no veio da oralidade, recuperando a maneira de narrar dos missossos e transportando-a para o universo da cultura letrada. O discurso proverbial, muito representativo das tradições orais, é, também, largamente utilizado no romance, constituindo-se, no dizer de Padilha:

a peça de resistência pela qual se sedimenta o edifício da sabedoria angolana. Chamam-se jissabu. As adivinhas, também muito populares e que se propõem como um passatempo, representando uma forma peculiar de interação comunitária; são conhecidas por jinongonongo ou, simplesmente, nongonongo. (PADILHA, 1995, p. 20 - destaques da autora).

Assim como são múltiplos os modos de pensar africanos, também o são as maneiras de falar. Para Santos:

Há, pois, na reinvenção dos provérbios feita pelos romances de Boaventura Cardoso, uma crítica à idéia de haver "uma unidade no modo de pensar africano". Ao contrário, a todo momento, a ficção cardosiana vai apontando atravessamentos culturais, hibridações e diferenças em diversas regiões angolanas e em determinados períodos da história de Angola. (SANTOS, 2008, p. 200 - destaques da autora).

Apenas para ilustração podem-se observar jissabus em "o fogo que te aquece pode te queimar" (CARDOSO, 2001, p. 137) e "não se deve procurar o leopardo no seu refúgio." (CARDOSO, 2001, p. 217). Ou ainda em "não te esqueças que o peixe morto vem sempre à superfície." (CARDOSO, 2001, p. 244). Verifica-se a presença de jinongonongo em "cão que se queima na pata fareja as cinzas? $\mathrm{Me}$ fala!” (CARDOSO, 2001, p. 90).

$\mathrm{Na}$ urdidura do texto construído por Boaventura Cardoso estão fortemente imbricados aportes aos mecanismos da tradição viva, a narrativa educadora dos missossos, e ao discurso proverbial, para dar conta de expressar, em uma língua portuguesa tensionada, uma literatura que transcenda a realidade, implodindo-a e tornando possível o nascimento de um outro lugar de fala, uma nova forma de agenciamento entre o binômio colonizado X colonizador. Daí, considerar esse texto como integrante do conjunto das literaturas menores é factível, pois a própria literatura menor, de acordo com a filosofia de Gilles Deleuze e Félix Guattari,

não pertence a uma língua menor, mas, antes, à língua que uma minoria constrói numa língua maior. E a primeira característica é 
que a língua, de qualquer modo, é afetada por um forte coeficiente de desterritorialização... A segunda característica das literaturas menores é que nelas tudo é político... O seu espaço, exíguo, faz com que todas as questões individuais estejam imediatamente ligadas à política. A questão individual, ampliada ao microscópio, torna-se muito mais necessária, indispensável, porque uma outra história se agita no seu interior... A terceira característica é que tudo toma um valor coletivo... As três categorias da literatura menor são a desterritorialização da língua, a ligação do individual com o imediato político, o agenciamento coletivo de enunciação... Só é menor o que é grande e revolucionário. (DELEUZE; GUATTARI, 2002, p. 38-41, 54).

O trabalho empreendido por Boaventura Cardoso engendra, perfeitamente, as categorias afetas às literaturas menores e, pode-se dizer, a uma alternativa de posicionamento face ao caos-mundo, conforme delineado por Glissant:

Chamo de caos-mundo... o choque, o entrelaçamento, as repulsões, as atrações, as conivências, as oposições, os conflitos entre as culturas dos povos na totalidade-mundo contemporânea... A paixão e a poética da totalidade-mundo podem indicar a relação com o Lugar e levar a abandonar, a transformar, os antigos reflexos... Nos dias de hoje, a verdadeira liberação de um povo no Todo-o-mundo é a possibilidade de refletir sobre sua função e agir no mundo. (GLISSANT, 2005, p. 98-120).

Em Mãe, materno mar é de clareza adamantina a felicidade do resultado do texto arquitetado numa poética da relação.

Boaventura Cardoso reúne, nas diversas classes da locomotiva, um rol de personagens de universos díspares e o convívio, forçado ou não, no decorrer do trajeto do trem, serve para exemplificar a Relação, conforme estabeleceu Glissant.

Tome-se como representativa uma pequena amostra dessas personagens: o Manecas que parte de Malange para "conhecer o mar" (CARDOSO, 2001, p. 215) e encontrar emprego, que era "menino do liceu, educado nas boas educadas maneiras, que frequentava os bons e os civilizados ambientes" (CARDOSO, 2001, p. 56) e "que mais sabia estudado os enciclopédicos marítimos saberes" (CARDOSO, 2001, p. 213); o agressivo, rico e arrogante Pai da noiva, cujo imaginário "estava ainda povoado de os muitos míticos heróis do 'western' americano com quem ele convivera nos livros e nos filmes" (CARDOSO, 2001, p. 141 - destaques do autor); as Endiabradas treze raparigas, as divas kamasutras, ou as "treze raparigas dos óculos escuros que estavam em todos os locais de animação" (CARDOSO, 2001, p. 109); o Profeta Simon Ntangu António, pescador e "um 
simples catequista, humilde, sem grandes pretensões na vida que não fossem pregar devotadamente a Palavra do Senhor" (CARDOSO, 2001, p. 236); o Pastor da Igreja de Jesus Cristo Salvador de Angola, que "lhe chamavam também de o brasileiro" (CARDOSO, 2001, p. 94) e que havia regressado "do estrangeiro" (CARDOSO, 2001, p. 96); os não crentes que eram "em minoria, liderados pelos camaradas do Partido [comunista]" (CARDOSO, 2001, p. 157) e, por fim, o velho Ti-Lucas, cego, cantor e pedinte, sobre o qual, posteriormente, se discutirá com maior detalhamento.

Todos esses seres são colocados em choque, têm suas vidas entrelaçadas, sentem repulsa, atração, resistem e, ao fazê-lo, operacionalizam o caos-mundo de Glissant.

\section{Poética da relação projetada na desmedida da desmedida}

Há resistências concretas que precisamos levar adiante.

No lugar onde estamos. (GLISSANT, 2005, p. 127)

As literaturas refletem o mundo real no seu modo peculiar de nomear, indiciar ou transfigurar o mundo circundante, ou até mesmo antevisionando realidades nunca antes vivenciadas (CARDOSO, 2010a, p. 24). É o próprio Boaventura, ao explicitar as temáticas e ideais da escrita por ele perfilhada, quem confidencia:

\footnotetext{
Se, em breves palavras, pudesse sintetizar o que são as minhas marcas literárias, diria que, a par da preocupação com a linguagem, há elementos que conformam a permanente interação entre o mundo visível e o invisível, a narrativa oralizante, a polifonia de ritmos e de vozes numa estrutura dialógica, em meio a uma permanente reencenação da tradição. (CARDOSO, 2010b, p. 39).
}

De acordo com Silva (2009, p. 168), a alternância na focalização operada no romance Mãe, materno mar, obtida com suas quase infinitas subnarrativas em encaixe, recupera o exercício da contação de estórias, da roda em que as várias vozes presentes se revezam num contar sem cronologia definida, sem uma linha reta.

Basicamente, o romance é dividido em três partes: "A terra", "O fogo" e "A água". Entremeado nesse fio condutor principal coexistem inúmeras subnarrativas encaixadas que dotam o enredo de uma polifonia discursiva bem ao sabor das rodas de contação de estórias. Como exemplo pode ser destacado um trecho da segunda 
parte, "O fogo", quando é feita uma fogueira em homenagem aos antepassados. Isso acaba por servir de pretexto para que se discorra sobre a história do fogo e o do nascimento da amizade entre o homem e o cão, como pode ser visto a seguir:

Naquele tempo, no tempo dos nossos antepassados, era uma vez um caçador, nome dele era o camarada Kakule, que andava então na floresta com o cão dele. Tinha chovido, fazia muito frio, e o camarada caçador estava procurar um meio qualquer de se aquecer, mas não dava encontro com nada. Então o camarada caçador pensou muito na faísca que vem dos céus, na faísca que cai nas árvores e faz fogo, pensou, pensou, pensou ainda na cabeça dele, e depois o camarada caçador falou assim no cão: "Ó meu cão, vai ainda lá em cima, no céu, e rouba a Deus o fogo para nos aquecermos.” E o cão falou assim, sim patrão, e o cão então subiu lá no céu, subiu, subiu, subiu ééé, e depois roubou a Deus uma brasa a arder, meteu a brasa na boca dele e desceu, desceu, desceu. Buazakatá! Quando Deus deu conta, oh!, já era tarde, o cão já tinha chegado na terra. Então, Deus, muito zangado, disse: "Fizeste a vontade ao teu dono, nunca mais te hás-de separar dele, até mesmo para te alimentares terás de contar com o teu dono. Estás condenado a depender sempre dele." Foi assim então que o homem e o cão se tornaram amigos de unha e dedo, inseparáveis, desde aqueles tempos antigos, no antigamente dos nossos mais-velhos. (CARDOSO, 2001, p. 192-193).

Nesse esteio, Boaventura Cardoso reativa o imaginário coletivo dos povos banto-africanos, fissurando a manipulação dos discursos do poder e instaurando outras "verdades" possíveis (SANTOS, 2008, p. 31). Pode-se constatar a validade de uma outra matriz de conhecimento, por exemplo, na passagem em que o trem, avariado, dessa vez estaciona em Cacuso. Esgotadas as tentativas de cada líder religioso em solucionar, cada um segundo sua fé, a avaria e fazer a locomotiva retomar o funcionamento, se veem impelidos a buscar guarida no saber tradicional e, mais uma vez, Ti-Lucas é consultado:

E então Ti Lucas, o ceguinho, que circulava por entre aquela multidão a parar e a cantar e a receber dinheiro, lhe abordaram numa comissão de três pessoas que em nome daquele povo andante e viajante lhe pediu Ti Lucas faz favor só nos descobrir quem que está ainda enguiçar no comboio. O ceguinho parou de cantar, reflectiu, cofiou a barba dele branca, e falou então sério que era necessário que alguém fosse por aqueles matos fora até encontrar uma gruta onde estavam os mikuyus, ndokis, basimbis, mintadis e mikissis, os espíritos e as mágicas estatuetas, que tinham de ser destruídos, que a gruta tinha de ser limpa de os muitos amuletos, que tudo isso tinha sido lá posto por gente malfeitora que não queria que o comboio saísse de Cacuso. Ih! E assim sendo se fez. 
Líderes religiosos se reuniram e decidiram então resolver juntos o problema... No dia seguinte, muito cedo, a brigada entregou-se com afinco ao trabalho e em menos de uma hora estava a avaria reparada. (CARDOSO, 2001, p. 85, 86).

O aparato de que se vale Boaventura Cardoso para rasurar o discurso oficial é erigido no seio da própria língua portuguesa, tornando-a não mais aquela standard, senão outra. Ao proceder dessa forma, o autor viabiliza a Relação em toda a sua força poética como um estratagema de autossalvação da nação angolana. De acordo com Glissant (2005, p. 118), só é possível salvar uma língua se não se deixa perecer as demais. Do mesmo modo, só se poderá salvar uma nação ou etnia se todas, juntas, coexistirem. É a isso que esse teórico denomina Relação. Nesse sentido:

Durante muito tempo... a errância ocidental, que foi uma errância de conquistas, uma errância de fundação de territórios, contribuiu para realizar o que hoje chamamos de "totalidade-mundo"... O que constitui o "Todo-o-mundo" não é o cosmopolitismo, que é uma transformação negativa da Relação. O que constitui o "Todo-omundo", é a própria poética da Relação, que permite sublimar, em pleno conhecimento de si e do todo, o sofrimento e a anuência, o negativo e o positivo, ao mesmo tempo... Nenhuma operação global política, econômica ou de intervenção militar é capaz de começar a distinguir, minimamente, a menor solução para as contradições desse sistema errático que é o caos-mundo, se o imaginário da Relação não repercutir sobre as mentalidades e as sensibilidades das humanidades de hoje, para levá-las a verter o valor poético, isto é, para considerar-se, humanidades e não mais Humanidade, de uma maneira nova: como rizoma e não mais como raiz única. (GLISSANT, 2005, p. 105-107).

Perspectivar a teoria de Glissant na direção da totalidade-mundo leva, naturalmente, ao enredo de Mãe, materno mar. Nele, nada foi considerado trivial, nenhum dos falares possui gradação em importância e, tampouco, nenhuma verdade é absoluta, não importa se pertencente à tradição ou a cultura letrada. Tudo está em Relação.

É o que acontece, por exemplo, quando se dá o misterioso casamento da noiva com o Deus do fogo, de acordo com a explicação de Ti-Lucas. Ocasião em que se reúne, mais uma vez, o Conselho dos Doze, para tentar, novamente, retomar a viagem do comboio avariado. Somente em Relação aqueles passageiros conseguiriam aplacar a fúria da natureza, como pode ser visto no seguinte excerto: 
O Conselho dos Doze, entretanto, insistia em que era necessário fazer algo para serenar os espíritos dos antepassados, aquietar essas almas vagueantes que estavam afinal enguiçar naquela viagem desde Malange, que eram eles, os nossos antepassados, que reclamavam atenção, que, por isso, todos os passageiros lhes acompanhassem, que eles iam evocar todos os antigos mortos. E assim, nesse dia, a noite sendo, a fogueira crepitando no centro do largo, todos os passageiros conduzidos pelos mais-velhos do Conselho andaram por todas as carruagens, foram no largo, se abeiraram dos verdes matos, os carreiros, cantando, a banda de música a querer dar umas notas, mas o Conselho não aceitou, que os mortos não gostavam nada daquelas chinfrinadas, vamos só mesmo cantar, todos, cantando, com as vozes naturais, os coros todos... Cantando. Até mesmo Manecas e os camaradas do Partido cantaram, acreditando ou não na eficácia daquela evocação à memória dos antepassados. Que eles começavam a compreender, no fundo, que naquela viagem tudo podia valer desde que fosse para pôr o comboio em marcha. (CARDOSO, 2001, p. 202, 203).

De acordo com Chaves e Macêdo (2005, p. 255), é a energia da tradição oral que vem enriquecer o caudal discursivo que pretende dar conta de uma pluralidade de questões com as quais o país precisa se debater para alcançar a harmonia roubada pelos anos e anos de guerra. No mesmo tom defende Padilha:

A oralidade... é o alicerce sobre o qual se construiu o edifício da cultura nacional angolana nos moldes como hoje se identifica. Praticá-la foi mais que uma arte: foi um grito de resistência e uma forma de auto-preservação dos referenciais autóctones, frente à esmagadora força do colonialismo português. (PADILHA, 1995, p. 17).

Materializar a poética da relação é um exercício essencialmente visionário, no qual, como atesta Glissant:

Faz-se necessário captar a medida-desmedida da visão profética do passado e do imaginário da Relação acrescida do tratamento dos rastros/resíduos das condições iniciais, da imprevisibilidade e deste novo tecido que precisa ser criado, que não corresponde mais ao reflexo da essência mas à rede das relações, da relação com o outro e das relações com as outras culturas. O Todo-o-mundo é uma desmedida... Desmedida não porque seja anárquico, mas porque não existe mais a pretensão à profundidade, a pretensão ao universal, mas apenas a pretensão à diversidade. "Desmedida da desmedida. A primeira é a abertura total, e a segunda é o Todo-omundo." A literatura tomou esse caminho. (GLISSANT, 2005, p. 108-109, 112 - destaque nosso). 
A artesania linguageira operada em Mãe, materno mar formata uma desmedida da desmedida. A abertura total em consonância com o Todo-o-mundo é, num tom sobremaneira irônico, demonstrada no desfecho do romance, quando, finalmente, o comboio chega a Luanda. $\mathrm{O}$ ânimo da multidão que aguardava $\mathrm{o}$ agora Profeta Simon, carnavalescamente, foi assim desenhado:

Entretanto, a partir das proximidades do BNA até à Restinga, estava ainda tudo na mesma: a muita boa animação! Vinha o grupo carnavalesco Os Trapalhões da Ilha numa grande batucada, com milhares de adeptos em movimentado bloco, Nossa Senhora das Boas-Águas lhe transportavam no primeiro andor, Nossa Senhora do Cabo, Santo António de Lisboa e Santa Teresinha do Menino Jesus que lhes trouxeram, até Nossa Senhora da Muxima lhe foram mesmo lhe buscar, jura?, estó ta dizer, meu!, a rainha do grupo que lhes precedia, depois, num sexto andor, vinha então o Profeta - imagem dele toscamente esculpida em madeira -, bandeiras, as todas da terra misturadas com outras, até tinha uma das cinco quinas, descolorida, uma ala de pescadores dançando, duas alas de raparigas trajadas de peixeiras empunhavam cartazes com a cara do Profeta, uma dúzia de intelectuais, desgarrados, se atrapalhando no refrão... Mas aquela toda rodança foi sol de pouca dura. Meia hora mais tarde toda a Marginal era uma gritaria infernal. Morte ao Profeta! Morte ao Profeta! Se tinha algumas pessoas a se retirarem, maioria daquele povo queria ir ainda chegar até na Estação do Bungo para justiçarem no Profeta, aquele por quem tinham esperado tão ansiosamente. (CARDOSO, 2001, p. 291, 292).

O aparente absurdo dessa circunstância só pode ser obtido no construto literário alicerçado na poética da relação.

\section{Considerações Finais}

Todo o resto é Relação: abertura e relatividade. (GLISSANT, 2005, p. 127)

Uma faceta importante dessa estória está no percurso que alegoriza uma nação - nação angolana - que não sabe para onde vai. Nesse ínterim, chegar a Luanda não é chegar a um fim. Porque a cidade ainda não está concretizada. Assim como não estão todos os angolanos. O país está em momento de transição, principalmente no pós anos 80 e isso está muito bem representado, atesta Cesar (2010, p. 188), pelo trem descarrilado em certa etapa de seu trajeto em direção a Luanda. 
Segundo Fonseca $(2005$, p. 99, 100), a obra sub exame problematiza as transformações que se vão operando na Angola do pós Independência, em que se misturam vários processos culturais e se acentuam as imbricações típicas de um tempo marcado por intensas contradições. A viagem para Luanda é, portanto, o motivo que fará com que os processos de migração do meio rural para os grandes centros sejam o pano de fundo que se descortinará ao longo do romance. A desagregação da família, a conquista de novas conviç̧ões e a intervenção do fantástico, elos da realidade esfacelada e da esperança alimentada no porvir, costuram a narrativa. De natureza similar, sobre este aspecto, são as considerações de Gonçalves:

De fato, no seu percurso, o comboio/nação que inicialmente parte em ritmo vertiginoso, vai sofrendo sucessivas avarias mecânicas, agravadas por constantes tumultos nas três classes da sua composição, com suas correspondentes diferenças sociais e econômicas, de modo que a lentidão ou a paralisia parecem marcar uma viagem, ou um país assolado pela guerra e pelos descaminhos da sua condução política. (GONÇALVES, 2007, p. 409).

O que pode ser apontado como um elo entre essa multiplicidade de elementos é a forma de estruturação do texto, que busca uma matriz de pensamento angolana representada pela personagem Ti-Lucas, o cego que enxergava bem mais do que todos e que, conforme lembra Ferreira (2009, p. 1724), representa a figura dos mais velhos, a sabedoria, algo muito respeitado pelos angolanos. Essa espécie de xamã é quem lembra que é preciso recuperar uma voz da tradição para dar conta da realidade. A palavra enunciada por Ti-Lucas, essa espécie de vate popular,

torna-se mediadora (e pacificadora), num cenário particularmente marcado por disputas no campo religioso e político que agravam ainda mais a situação vivida pelo povo angolano na sua pós independência. A importância desta figura no romance não decorre, apenas, de valores morais que ela representa, mas da configuração discursiva que extravasa de sua fala e contagia todo o processo narrativo, que adota características típicas da narrativa griótica, expandindo-se para todo o romance numa polifonia em que se dá a oscilação entre a voz e a letra... Ti-Lucas é o cego que um dia pôde ver e trabalhar como um operário comum, desempenhando na narrativa o papel de alter-ego do narrador, através do qual se produz o discurso da ironia demolidora, enunciado pelo cego que vê melhor "por dentro", no contraponto com os fiéis, manipulados pelos seus líderes corrompidos. (GONÇALVES, 2007, p. 411, 413). 
Esse ceguinho, como também Ti-Lucas era chamado, era uma pessoa que gozava de muito respeito e simpatia. De cabelos brancos e aparência humilde, assim ele se pronuncia em sua primeira fala no romance:

- Muito obrigado. Agradeço pela confiança que depositaram em mim. Farei tudo o que estiver ao meu alcance para resolver o problema que nos divide. Diziam os nossos antepassados que numa querela não se separa o homem que está deitado do que está de pé, no meio da confusão não se distingue quem tem razão de quem não a tem. Para além disso, como vocês sabem, perante a morte somos todos iguais. Assim, neste caso que muito nos faz chorar, somos impotentes, reduzidos à nossa condição humana de simples mortais. Somos, por isso, todos iguais. Contudo, enquanto vivos temos deveres perante os nossos mortos. E um dever que os vivos têm é o de respeitarem a memória daqueles que partiram para a eterna viagem. É ou não assim?! (CARDOSO, 2001, p. 55-56).

De acordo com Padilha,

o missosso, visto como um instigante e milenar exercício de sabedoria que grita a força da vitória do velho (ordem angolana) sobre o novo (ordem européia)... O missosso, voz 'negra' da tradição oral de Angola, ganha da 'brancura' da letra, quando consegue resistir por séculos, apesar de não dispor, por muito tempo, dos meios de resgate do dito - letra e papel - do mundo branco-ocidental. (PADILHA, 1995, p. 52, destaques da autora).

A estória vale mais enquanto se percorre o trajeto de Malanje a Luanda. Quando se chega ao ponto final, Luanda, o objetivo da viagem, acaba por não se concretizar. Pois esse objetivo, assim como a história desse país, ainda não está totalmente claro. $\mathrm{O}$ que faz muito sentido quando se considera que a proposta não é trazer a noção de uma sociedade angolana já maturada e, sim, narrar uma consciência "nacional" em construção, que não tem nem a vaga ideia de em que porto irá ancorar.

Mãe, materno mar é um missosso, uma narrativa da fantasia, totalmente preenchida com elementos da cultura angolana, tanto na forma quanto no conteúdo. O texto oferece múltiplas entradas de leitura, inclusive uma abordagem social do contexto ao qual ele se refere num dado momento específico, que se coloca como um espelho no qual essa sociedade angolana poderá se refletir. E, dessa forma, a obra recupera, enquanto exercício de sabedoria, as marcas da tradição viva.

Isso nos permite concluir que Mãe, materno mar enceta uma escrita que dispõe em relação culturas assimétricas, em uma posição dialógica, para feitura de um mosaico da totalidade-mundo de matriz tipicamente angolana: o missosso. 


\begin{abstract}
This study aims to present a reading of the novel Mãe, materno mar, written by the Angolan writer Boaventura Cardoso, sustained by theoretical reflections on the notion of minor literature and the cultural production anchored in the oral traditions of the Angolan people, notably, the missossos. The intent is, mainly, to demonstrate that this novel allows, exemplarily, at least in the literary space, the materiality of what was named poetics of the relationship. It was possible to conclude that this work rescues, as an exercise of wisdom, marks of the live tradition. In addition to that, it broaches a writing that places disparate cultural relationships in a dialogic position for making a typically Angolan mosaic: the missosso.
\end{abstract}

Keywords: Angolan literature. Oral tradition. Minor literature. Poetics of the relationship.

\title{
Referências
}

ANDRADE, Fernando Costa. Entre a voz do fogo e o eco materno do mar: antigos capilares da terra. In: CHAVES, Rita; MACÊDO, Tania; MATA, Inocência (Org.). Boaventura Cardoso: a escrita em processo. São Paulo: Alameda, 2005. p. 61-64. CARDOSO, Boaventura. Mãe, materno mar. Porto: Campo das Letras, 2001. CARDOSO, Boaventura. Saudação do Ministro da Cultura de Angola. In: SECCO, Carmen Lucia Tindó; SALGADO, Maria Teresa; JORGE, Silvio Renato (Org.). Pensando África: literatura, arte, cultura e ensino. Rio de Janeiro: Fundação Biblioteca Nacional, 2010a. p. 23-25.

CARDOSO, Boaventura. Temáticas e ideais de escrita que perfilho. In: SECCO, Carmen Lucia Tindó; SALGADO, Maria Teresa; JORGE, Silvio Renato (Org.). Pensando África: literatura, arte, cultura e ensino. Rio de Janeiro: Fundação Biblioteca Nacional, 2010b. p. 35-39.

CESAR, Rafael. A alegórica Mãe, materno mar angolana e a importância da obra de Boventura Cardoso na escrita da história de Angola. Revista do Núcleo de Estudos de Literatura Africana da UFF. Rio de Janeiro, v. 3, n. 5, nov. 2010. p. $185-189$. 
CHAVES, Rita; MACÊDO, Tania. Breve apresentação dos textos de Boaventura Cardoso. In: CHAVES, Rita; MACÊDO, Tania; MATA, Inocência (Org.). Boaventura Cardoso: a escrita em processo. São Paulo: Alameda, 2005. p. 249255.

DELEUZE, Gilles; GUATTARI, Félix. Kafka: para uma literatura menor. Lisboa: Assírio \& Alvim, 2002. 148 p.

FERREIRA, Guadalupe Estrelita dos Santos Menta. A simbologia do sagrado e do profano: uma viagem no comboio de Mãe, materno mar. In: CONGRESSO INTERNACIONAL DA ASSOCIAÇÃO BRASILEIRA DE PROFESSORES DE LITERATURA PORTUGUESA, 22., 2009, Anais... Salvador: ABRAPLIP, 2011. p. 1716-1725.

FONSECA, Maria Nazareth Soares. Processos narrativos e recriações linguageiras na obra de Boaventura Cardoso. In: CHAVES, Rita; MACÊDO, Tania; MATA, Inocência (Org.). Boaventura Cardoso: a escrita em processo. São Paulo: Alameda, 2005. p. 89-106.

GLISSANT, Édouard. Introdução a uma poética da diversidade. Juiz de Fora: Ed. da UFJF, 2005. 172 p.

GONÇALVES, Virgínia Maria. O Tirésias angolano em Mãe, Materno Mar de Boaventura Cardoso. In: CHAVES, Rita; MACÊDO, Tania; VECCHI, Rejane (Org.). A kinda e a missanga: encontros brasileiros com a literatura angolana. São Paulo: Cultura Acadêmica, 2007. p. 407-421.

KANDJIMBO, Luís. Mãe, materno mar: caos, incerteza e religiosidade. [20-?]. Disponível em: <http://www.nexus.ao/kandjimbo/recensoes/incerteza.htm>. Acesso em: 30 ago. 2011.

PADILHA, Laura. Cartogramas: ficção angolana e o reforço de espaços e paisagens culturais. Alea. Rio de Janeiro, v. 7, n. 1, jun. 2005. Disponível em: $<$ http://www.scielo.br/scielo.php?pid=S1517106X2005000100009\&script $=$ sci arttext>. Acesso em: 30 ago. 2011.

PADILHA, Laura Cavalcante. Missosso: literatura tradicional angolana. [Primeiro] segmento: exercícios de sabedoria. In: PADILHA, Laura Cavalcante. Entre voz e letra: o lugar da ancestralidade na ficção angolana do século XX. Niterói: Ed. da UFJF, 1995. p. 15-52.

SANTOS, Olimpia Maria dos. A alegórica Mãe, materno mar angolana. Rio de Janeiro: Caetés, 2008. 247 p. 
SARAIVA, Sueli da Silva. A experiência do tempo em dois romances africanos: Um rio chamado tempo, uma casa chamada terra e Mãe, materno mar. 2008. 147 p. Dissertação (Mestrado) - Faculdade de Filosofia, Letras e Ciências Humanas, Universidade de São Paulo, São Paulo. 2008.

SECCO, Carmen Lúcia Tindó Ribeiro. A presença de religiões, mitos e sonhos em letras e telas angolanas. In: CONGRESSO INTERNACIONAL DA ASSOCIAÇÃO PORTUGUESA DE LITERATURA COMPARADA, 4., 2001. Anais... Évora: Universidade de Évora. Disponível em: <http://www.eventos. uevora.pt/comparada/VolumeI/A\%20PRESENCA\%20DE\%20RELIGIOES. pdf $>$. Acesso em: 30 ago. 2011.

SECCO, Carmen Lucia Tindó Ribeiro. Os recantos da memória e os cantos e encantos da linguagem (Boaventura Cardoso e Guimarães Rosa: aproximações possíveis). In: LEÃO, Ângela Vaz (Org.). Contatos e ressonâncias: literaturas africanas de língua portuguesa. Belo Horizonte: PUC Minas, 2003. p. 237-245. SILVA, Renata Flávia da. Um trem pras estrelas. Revista do Núcleo de Estudos de Literatura Africana da UFF. Rio de Janeiro, v. 2, n. 3, nov. 2009. p. 168-171.

Submetido em: 16 de junho de 2015. Aceito para publicação em: 09 de outubro de 2015. 
